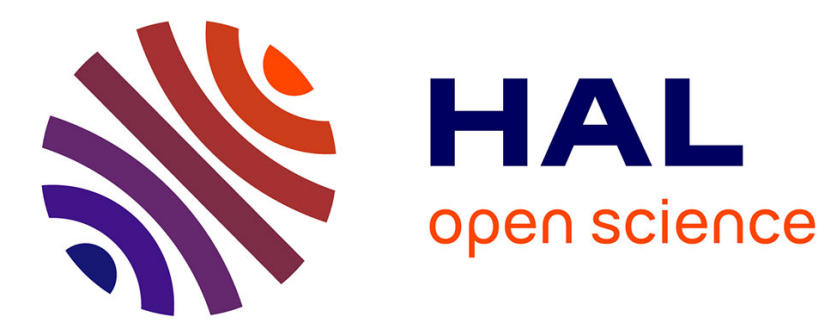

\title{
Inspiration, images and design : an investigation of designers' information gathering strategies
}

Céline Mougenot, Carole Bouchard, Améziane Aoussat, Steeve Westerman

\section{To cite this version:}

Céline Mougenot, Carole Bouchard, Améziane Aoussat, Steeve Westerman. Inspiration, images and design: an investigation of designers' information gathering strategies. Journal of Design Research, 2008, 7 (4), pp.331-351. 10.1504/JDR.2008.026987 . hal-00915107v2

\section{HAL Id: hal-00915107 \\ https://hal.science/hal-00915107v2}

Submitted on 13 May 2014

HAL is a multi-disciplinary open access archive for the deposit and dissemination of scientific research documents, whether they are published or not. The documents may come from teaching and research institutions in France or abroad, or from public or private research centers.
L'archive ouverte pluridisciplinaire HAL, est destinée au dépôt et à la diffusion de documents scientifiques de niveau recherche, publiés ou non, émanant des établissements d'enseignement et de recherche français ou étrangers, des laboratoires publics ou privés. 


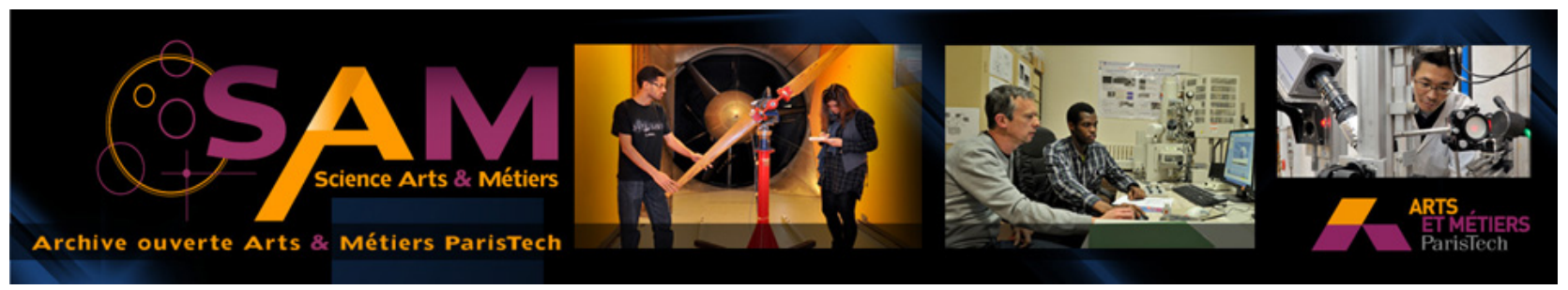

Science Arts \& Métiers (SAM)

is an open access repository that collects the work of Arts et Métiers ParisTech researchers and makes it freely available over the web where possible.

This is an author-deposited version published in: http://sam.ensam.eu

Handle ID: .http://hdl.handle.net/10985/7602

\section{To cite this version :}

Céline MOUGENOT, Carole BOUCHARD, Améziane AOUSSAT, Steve WESTERMAN Inspiration, images and design : an investigation of designers' information gathering strategies Journal of Design Research - Vol. 7, n4, p.331-351- 2008 


\title{
Inspiration, images and design: an investigation of designers' information gathering strategies
}

\section{Céline Mougenot ${ }^{*}$, Carole Bouchard and Ameziane Aoussat}

LCPI Design Lab,

Arts \& Metiers ParisTech,

151 Bd de l'Hôpital,

75013 Paris, France

E-mail: celine.mougenot@paris.ensam.fr

E-mail: carole.bouchard@paris.ensam.fr

E-mail: ameziane.aoussat@paris.ensam.fr

*Corresponding author

\section{Steve Westerman}

Psychology of Design Group,

Institute of Psychological Sciences,

University of Leeds,

Leeds LS2 9JT, UK

E-mail: s.j.westerman@leeds.ac.uk

\begin{abstract}
Computational tools should efficiently support, and even enhance, designers' creativity. As a ground for such developments, design cognition studies aim at describing designers' mental strategies within the design process. So far, most researches have been focused on the idea generation phases, e.g. sketching activity, which is explicit enough to be observed and described. However, the early stages of design remain incompletely understood, while the informational phase is identified as a crucial step of the design process. In this context, our objective is to identify and evaluate inspirational information used by designers before generating ideas, and to describe how inspirational information is used. In this article, we report a two-part study (interviews and experimental protocol) carried out with professional designers. The main outcomes demonstrate that traditional and electronic resources are not used in the same way by designers. We also show that information gathering strategies are strongly influenced by designers' preference.
\end{abstract}

Keywords: creativity; design; design cognition; design computing; images; information retrieval; inspiration; kansei; sectors of influence.

Reference to this paper should be made as follows: Mougenot, C., Bouchard, C., Aoussat, A. and Westerman, S. (2008) 'Inspiration, images and design: an investigation of designers' information gathering strategies', J. Design Research, Vol. 7, No. 4, pp.331-351.

Biographical notes: Céline Mougenot graduated in Mechanical Design from INSA Lyon and worked as a CAD engineer at Dassault Systemes. After a 4-year experience in the industry, she currently is a $\mathrm{PhD}$ candidate in Design 


\section{Mougenot et al.}

Science. Her research interests are design thinking and cognition, creativity in design and computational tools for designers.

Carole Bouchard is an assistant professor at Arts \& Metiers ParisTech. Her research interests are design methodologies, creativity, kansei engineering and emotional design. Based on several studies with design practitioners, she developed design methodologies integrating designers' cognitive activity. She has previously published in journals such as Int. J. Product Development, Journal of Design Research and Int. J. Vehicle Design.

Ameziane Aoussat is a full-time professor at Arts \& Metiers ParisTech, and head of LCPI Design Lab. His area of research is the optimisation of the design process. In the last 18 years, he has advised more than $30 \mathrm{PhD}$ theses and published in journals such as Journal of Engineering Design, Journal of Design Research and Int. J. Computer Applications in Technology.

Steve Westerman is a senior lecturer in Human Factors at the University of Leeds, UK. His current research interests include information retrieval, usability testing, and affective design of both artifacts and interfaces. His research has been published in a range of journals, including Ergonomics, Acta Psychologica, Human Factors, and the Int. J. Human-Computer Studies.

\section{Introduction}

\subsection{Context: developing tools to enhance creativity in early stages of design}

Computational tools can now support most human activities, including design. A special focus on early phases of design, as the informational phase, would be extremely useful for developing computational tools that efficiently support designers' creativity (Schneiderman, 2000). We think that designers' creativity can be enhanced by computational support. As suggested by Nakakoji, Yamamoto and Ohira (1999), computational systems help to provide designers with huge databases of visual and textual materials relevant in creative design activities. Some tools have been developed to support inspiration, based on the idea that designers need large databases containing images of precedents, i.e. previously designed artifacts, to support the evocation process (Keller, Stappers and Hoeben, 2000; Keller, 2005) (Guénand and Capell Zapata, 2003) (Pasman, 2003) (Restrepo, 2004). Based on the same vision, our research context is TRENDS project, a three-year project supported by the European Union whose objective is to design an image-retrieval software dedicated to designers. Designers intensively use images in their professional activities and the TRENDS computational tool will support the image-retrieval activity in design and its cognitive aspects, including evocation, analogy-making and concept generation (Bouchard et al., 2008). A pre-requisite to the development of digital inspiration-support tools is to understand the inspirational process in design, especially involving a cognitive approach. Bonnardel and Marmèche (2005) studied the evocation process in creative design and proposed two ways of leveraging designers' creativity with digital tools: to support designers in taking advantage of inter-domain sources of information and to support designers in adopting various points 


\section{Inspiration, images and design}

of view. The study presented here especially addressed the first issue, by comparing magazines and websites in the way they support designers in retrieving sources of inspiration. Today's computational tools support detailed design phases better than conceptual design phases, mostly because conceptual phases in design are not so explicit, they are 'hidden' in designer's mind and thus, difficult to describe, model and support. Therefore, design research with a cognitive approach is still necessary when aiming at developing breakthrough digital tools to support designers' inspiration and creativity.

\subsection{A cognitive approach to design early stages}

Design thinking has been attracting more and more attention from researchers since Donald Schön (1983) and his contribution to the understanding of what practitioners do and think and the development of 'reflection-in-action' and 'reflection-on-action' notions. Lawson's (1980) work was more specifically focused on architectural activities; in an attempt to 'demystify the design process'. Lawson (1980) observed architectural activities and demonstrated the importance of sketching within the design process, as a tool for an iterative idea formalisation. In 1995, the Delft protocol laid the foundations for research dedicated to design thinking (Cross, Christiaans and Dorst, 1996) and the research community became aware that creativity in design was a research issue in itself, with particular features. To get an understanding of the creative process in the design context (see also Nagai, Candy and Edmonds, 2003; Visser, 2006) the inspirational process was studied by Eckert and Stacey (2000), who stressed that designers need to devote some of their working time to browse inspirational materials, and also by Ansburg and Hill (2003) who showed that creative designers use their attentional resources to cover a wide range of sources of information.

Creativity in design also involves a specific cognitive feature: analogical reasoning; many studies demonstrated that designers make an intensive use of analogies in order to adapt design features from other fields to their own design problem. From a more descriptive point of view (Leclercq et al., 2002) described the way designers use analogies. Bonnardel and Marmèche (2005) showed that the most creative analogies are those made between the most distant domains and that analogies can be performed at various levels (functional, structural, and affective). Analogical thinking is often triggered by visual stimulation, it has been shown that pictures and images are a major way of stimulating designers creativity (Casakin and Goldschmidt, 1999; Goldschmidt and Smolkov, 2006). Besides visual materials, the importance of words was emphasised by (Dong, 2006); to him, 'language serves as representations of ideas and concepts through linguistic behaviours that represent the structure of thought during the design process'. Today, visual materials and linguistics materials have been identified as major vectors of design creativity. However, we still lack an acute description of the roles of pictures, words and pictures-and-words relationships within the designers' cognitive process.

Some studies have attempted to create links between the visual characteristics of products and descriptive words, in the frame of design, by building design precedents classifications (Keller, 2005). Subjective experience, either on the part of designers or product users' can be taken into account and design characteristics can be linked to abstract notions, such as feelings or emotions. Kansei studies (Bouchard, Lim and Aoussat, 2003) aim to describe the role of designers' feelings in relations to product development. 


\section{Mougenot et al.}

Recent studies in Kansei were reported by (Levy and Yamanaka, 2006). However, so far these studies mainly focus on the idea generation phase or in the design evaluation phase. An emergent trend is to study the relationships between the information provided to the designers and the generated design solutions. A recent study by Perttula and Sippilä (2007) focused on the impact of exposure to design solutions and demonstrated that showing images of original design solutions to a problem would support designers in finding other original solutions. We propose that the relationships between information content/format and idea generation in design require further investigations.

\subsection{Research question}

To develop user-centred creativity-support systems, including image-retrieval systems, we need to investigate designers' cognitive activity and, in our case, how inspirational resources are used by designers. Our global research agenda aims to assess the impact of inspirational information onto design creativity; in this framework, the goal of the study presented in this article is to investigate the nature of the inspirational resources collected by designers in the early stages of the design process and the strategies followed in their information-retrieval activity.

In the 1990s, a major visual reference for designers was 'MTV's video style' (Kolli, Pasman and Hennessey, 1993). Since this time, professional activities have been deeply transformed with the introduction of the internet in most countries. Most design agencies use online tools and websites (Keller et al., 2005), and one of the most popular imageretrieval tools among designers is Google Images (http://images.google.com/). One of its most appealing characteristics is a 5-billion-image database, the largest in the world as of May 2008. The internet is the biggest provider of visual information, but, in its current state, is it really relevant for use in professional design activity? Does it provide a sufficiently inspirational medium for designers? Thus, an important research issue concerns the influence of inspirational materials, mainly visual materials, on designers' subjective impressions/experiences of design features and their creativity.

In the investigation reported here, we address designers' activity in the information gathering phase (collecting images), with a special focus on the way they select inspirational materials from 'traditional' resources, such as printed magazines versus new resources, such as websites. In addition, we examined the level of 'abstraction' of images retrieved from magazines and from the web. It can be argued that visual inspiration/images provide information 'on-demand', at the level of abstraction wanted by designers, from a low-level of abstraction (colour, texture) to a high-level of abstraction (emotion, atmosphere, value). However, it is possible that the medium will influence the selected level of abstraction.

To investigate these issues we carried out a study in two phases. First we organised interviews with designers to investigate the early phases of the design process (March 2006) and to get an overview of the inspirational process in design. Then we designed an experimental protocol for an on-site qualitative study (July 2006), to get a more detailed understanding of the inspirational resources and inspirational strategies used by designers. This focused on a comparison between the inspirational resources found from magazines and the ones found from websites, and the strategies followed by designers when retrieving inspirational images. This study was performed with the participation of professional designers from two automotive design companies located in Italy, namely FIAT and Stile Bertone. 
Inspiration, images and design

\section{Phase 1: overview of the inspirational process in design}

\subsection{Protocol: interviews}

To investigate the inspirational process, a first phase consisted in interviews that were carried out with 32 professionals from FIAT and Stile Bertone. The objective of the interviews was to describe the nature of the inspirational resources that are collected and used by designers in their daily activities. The participants belonged to departments in charge of design early phases. Twenty-one participants were from the Design department; six participants were from the Marketing department; and five participants were from the Innovation department. The participants were interviewed in groups of two. The interviews were semi-structured and each lasted approximately 1 hour. To be ready for the interviews, the participants had to complete in advance a 13-page printed booklet with sketches and/or text, the booklet questions were the same as the interview questions. Questions included:

- Where do you catch sources of information and/or inspiration (places, media, favourite magazines, favourite websites...)?

- In which fields/sectors do you search for inspiration (organic shapes, aeronautics...)?

- Where do you keep and organise your visual materials?

- Describe the steps of exploration of your collections of images.

\subsection{Outcomes}

Browsing magazines was seen as a usual and daily activity by designers. The designers claimed that reading magazines is the 'traditional' way of being kept informed about trends and design news. However, they also acknowledged that the internet is becoming more and more widely/frequently used in information gathering/monitoring activities. All of the designers used it on a daily basis as well. We were interested in knowing whether internet and pictures search engines, such as Google Images, are used differently from the printed media in the informational phase of designers' jobs.

\subsubsection{About the inspirational process}

The inspirational process is continuous - gathering information is a continuous preparation for the designers, in order to be highly creative once the brief is announced. Between the reception of a design brief and concept generation, the 'spare' time available for collecting information is very tight. Most of the time is spent in creative activities; so designers use experience and knowledge gained before the project to direct information gathering. In this way, when the project has started, they are able to restrict gathering to relatively small amounts of 'external' information. Most of the designers stressed the fact that inspiration does not fit the constraints of a '9-to-5-job', but is rather a continuous, 


\section{Mougenot et al.}

and almost unconscious, activity that may take place while watching cars on the street, taking a stroll in the countryside or visiting buildings. Capturing information from the everyday life, and storing it mentally, is part of the designers' job. A manager sees the continuous update of cultural knowledge as a keystone for design work, because 'the idea will always be the outcome of [our] experiences'.

Design briefs vary in the types and quantity of information provided - often the brief focuses on key demographics of anticipated users (car owners) and technical details. A design brief can be as short as two A4-pages, or sometimes as long as a book, containing information about the dimensions (car packaging), the targeted market sector, what the design should not be like (e.g. 'not like such or such car model'), required technologies, competition (or anticipated competition), a functional description, regulations... Sometimes additional material is given relating to specific design directions that are preferred or design directions to be avoided. This is often done with specific reference to car images. More detailed information can be given, including images describing semantic concepts or emotions that the design should convey (e.g. pictures of a 'happy family'), or images illustrating key characteristics of the demographic group(s) which the design is targeted.

The early steps of creative activities are mainly individual - after receiving the brief, designers would start to develop individual designs, for a period of approximately one week, up to three weeks. Once initial designs are completed, they would be brought to a design meeting at which a small number, possibly one, of design proposals would be selected by managers for further development. At this point, some of the designers might make use of images illustrating sources of inspiration, through building trend boards for instance. After final concept(s) selection, designers would drop the non-selected design proposals and work collectively on the selected design proposal(s).

An incubation time is essential - concept generation is carried out over a few days only. In this timeframe, designers' creative activities reach their peak of intensity. During this time the importance of an 'incubation' period was mentioned by several designers, who find it useful to go away from materials/designs for a while and then come back to them with a fresh view. They deliberately take a break and come back to the design later.

Junior designers rely on inspirational resources more than senior designers - expert designers claimed that their experience and their inner knowledge were sufficient when they had to generate new concepts. Having received the brief proficient, designers were 'sure to be able to produce new concepts, because of long experience'; another reported that he just 'looks into [myself]'. 'Experience is enough; I don't need to go to a special place to get information'. For these reasons, the gap between young designers and expert designers is obvious: they manage inspiration and information with a different level of easiness. 'Young' designers might feel less self-confident than their expert colleagues. It seems there is a greater need for novice or young designers to have access to information and inspirational materials. This may occur as they attempt to compensate for their lack of experience. However, in the case of electronic resources, it is also possible that it occurs due to greater familiarity and liking for new technologies. 


\section{Inspiration, images and design}

\subsubsection{About inspirational media and computational tools}

Visual sources are predominant - inspiration comes to designers through their five senses; however, some senses are predominant over the others. According to the designers, the design process is image-oriented rather than text-oriented, and that is why magazines, books and the internet are the most used sources of information.

Magazines and design books are still the main sources of inspiration - magazines are often used as a source of information. They can be accessed more flexibly than the internet (anyplace, anytime) and designers seem better able to memorise what they saw in magazines. Besides, five participants clearly expressed that reading a magazine is a pleasurable moment, which is not the case while browsing the internet. They seem to enjoy the fact that they have to manipulate physically something and find it pleasant to touch. Designers also stress on the fact that magazine information is always linked with a date, so they easily know whether the information is up-to-date.

Internet: a promising outsider - the internet has become the most commonly used electronic tool in design offices and design agencies. Designers use it on a daily basis, as a complementary tool to books or magazines, but also as an inspirational tool in itself. For all the participants interviewed, the internet is now a natural extension of their working environment. However, low resolution can be a problem when using images from the web (Figure 1).

Computers as design-supporting tools - all participants used the internet in their everyday design job. In parallel to the internet development, we observe that designers use digital cameras a lot, to keep visual records of motor shows, of architecture, and so on. In fact, most of the designers have electronic databases of images that they use. However, these are not particularly structured for the project they are working on. Some designers reported having no need for storing information or collecting images after a project ended. We interviewed people from their 20s to their 50s; they all see internet as a useful tool for finding information.

Figure 1 Booklet sample/'Where do you find sources of inspiration'

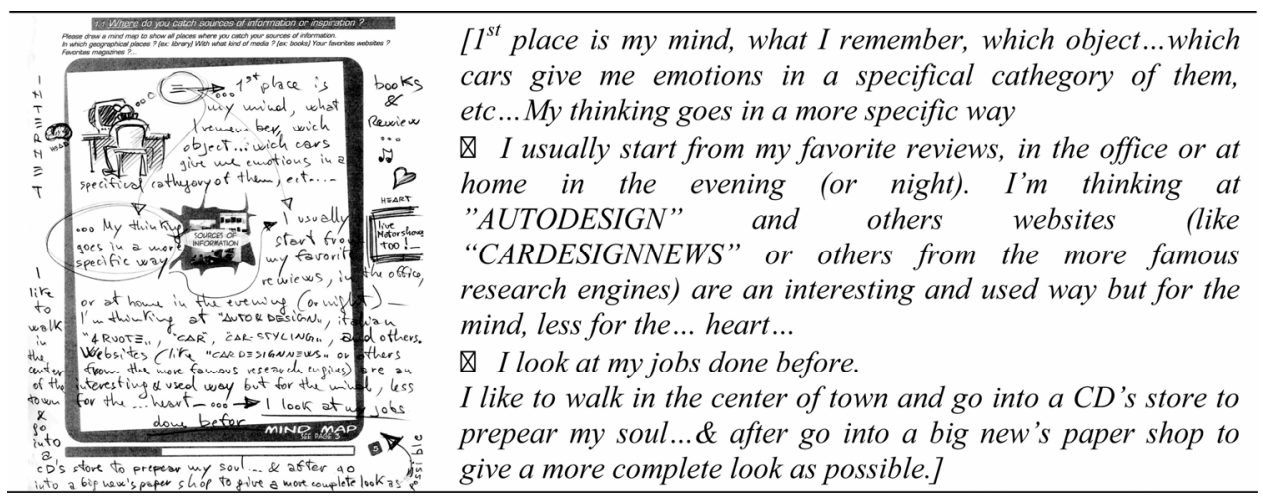




\section{Mougenot et al.}

Internet as a brainstorming tool - the Google search engine is often said to be used as part of 'brainstorming'. A rather 'loose' Google search can be useful in retrieving items that the designer did not have in mind but that are inspirational in relation to the design brief. When using the internet, many designers find interesting things they were initially not looking for. This approach to information gathering seems to be particularly useful in the first phase of design projects, when the research benefits from being as 'wide' as possible. Then, in a second phase, the research is more focused in order to find relevant materials in more specific sectors of influence.

\subsubsection{Inspirational sectors}

Car-design precedents are major influences for automotive designers - Figure 2 shows a representative case (from one designer) of sources of inspiration used in car-design projects: car-design precedents (previous creations) and car-related fields (races, motorways) are the major influences. Some designers assemble images of cars that are consistent with the brief to get an idea of what has being done. The main information search by designers is focused on their own car-design precedents and those of competitors. They may find examples of cars that they do not like. These images would mainly be used as a 'benchmark' for quality/direction, as well as sources of inspiration for design. For this purpose, the information should be relevant to the target (cars) but not too similar. However, some projects at FIAT were based on a sense of history of a particular car (e.g. 'FIAT 500'), in which case, images of the specific car would become more central to the process.

Panorama of inspirational sectors - although car-design precedents have a huge impact on car design projects (see Figure 3), designers also get inspiration from other fields: e.g. architecture, furniture, animals. Participants often quote similar sources of information when asked about inspirational sectors, with 'car design' and 'architecture' being the most quoted. Fields of inspiration were sometimes influences by the brand of the design. According to one participant, FIAT designs tended to be inspired by architecture, ALFA ROMEO by sculpture and LANCIA by fashion.

Figure 2 Booklet sample/'Where do you find sources of inspiration'

\begin{tabular}{|c|c|}
\hline $\begin{array}{l}\text { majo } \\
\text { at work }\end{array}$ & $\begin{array}{l}\text { [Races } \\
\text { Music, music, music } \\
\text { Motorway } \\
\text { Parkings } \\
\text { Nature } \\
\text { Motorshows } \\
\rightarrow \text { My camera } \\
+ \text { Internet for more impression } ₫ \text { Google } \\
+ \text { design books at work] }\end{array}$ \\
\hline
\end{tabular}




\section{Inspiration, images and design}

Figure 3 Inspirational domains spontaneously quoted by the 32 participants (see online version for colours)

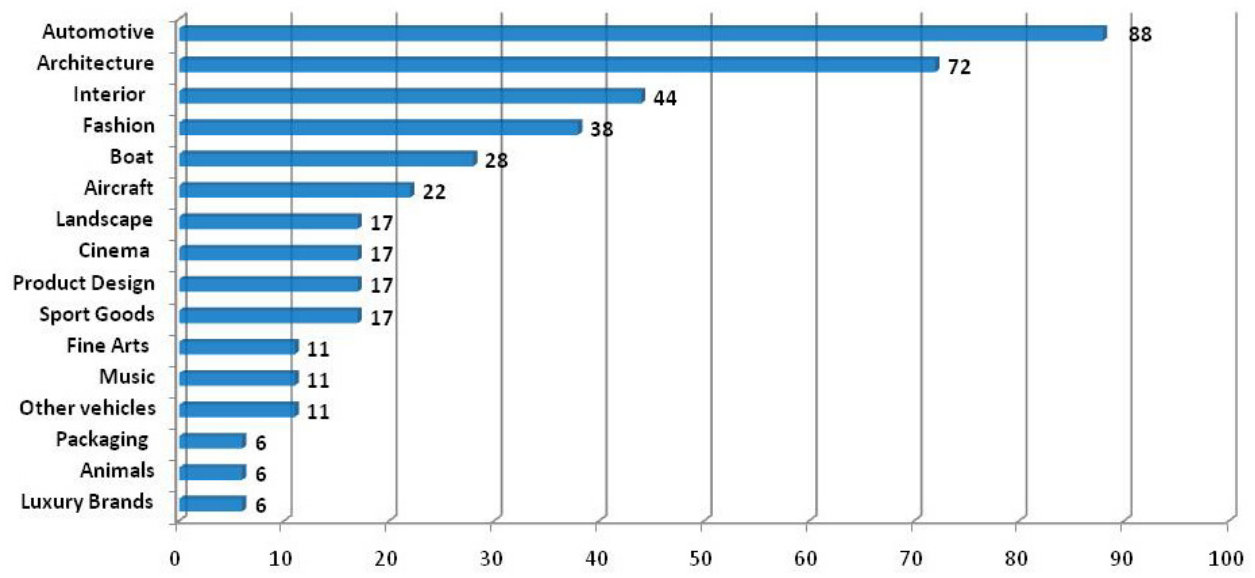

$x$-axis: percentage of participants quoting the domain - $y$-axis: domains quoted by participants

The interviews provided an understanding of the activity of collecting inspirational materials and the sources used by designers and innovation-related professionals. They also enabled us to draw up a list of inspirational materials, magazines and websites that would be used in the experiment that is described below.

\section{Phase 2: comparison of inspirational resources}

After getting an overview of the inspirational process using semi-structured interviews, the second phase of this study was a laboratory-based investigation of designers' ways of selecting inspirational materials retrieved from magazines and websites, and of associating words and pictures. The goal of this experimental component was twofold:

1 To describe the cognitive process of designers when searching for images and texts in the frame of their inspirational process.

2 To compare the ways magazines on one hand and websites on the other hand contribute to supporting designers' creativity.

This study was based on the following premises: in the early phases of design, the activity of browsing is largely based on individual strategies that relate to designers' feelings towards the product (or Kansei). It was also assumed that new digital tools, such as the internet, would impact the informational phase in design projects.

\subsection{Protocol: exploration and categorisation of visual resources}

The sample comprised four male designers who participated in Phase 1 (interviews). The nationality of the designers was Italian (2), German (1) and French (1). Ages of participants ranged from 27 to 33 years old (mean $=29.8$ years). Professional design experience ranged from 3 to 7 years (mean $=5.3$ years). All participants were proficient in English, the language that was used for giving experimental instructions. In this article were refer to the participants as 'Designer 1', 'Designer 2', 'Designer 3' and 'Designer 4'. 


\section{Mougenot et al.}

Each experimental session was carried out by one experimenter who interacted with one designer for approximately $120 \mathrm{~min}$. The sessions were video-taped. In this article, we present two assignments that were performed by the participants. Both assignments were designed as to be as close as possible to a real professional activity. The experiments were performed in a lab-like room, inside the designers' usual environment (company facilities). The designers were asked to complete the experiment as if they were performing their usual activities of trends and design information watching (Figure 4).

\subsubsection{Identification and categorisation of inspirational content}

The exploration of visual resources consisted of participants freely browsing inspirational materials that were provided, i.e. six printed magazines dealing with automotive design, fashion, interior design, art and architecture and 10 websites dealing with automotive design, fashion, product design, as listed in Table 1.

Figure 4 A participant annotating and grouping images (see online version for colours)
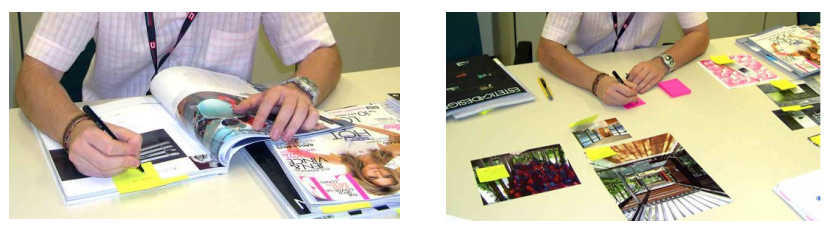

Table 1 Magazines and websites provided to the participants for a shuffle exploration

\begin{tabular}{|c|c|c|}
\hline Magazine name & Issue reference & Sector \\
\hline$\overline{\text { Carl*s Car }}$ & $\mathrm{N}^{\circ} 16$ - July 2006 Issue (131 pages) & $\begin{array}{l}\text { Automotive Design and } \\
\text { Lifestyle }\end{array}$ \\
\hline DAM & $\mathrm{N}^{\circ} 7$ - July/August 2006 Issue (168 pages) & Design, Art and Architecture \\
\hline ELLE & August 2006 Issue (218 pages) - UK Edition & Fashion, Lifestyle and People \\
\hline $\begin{array}{l}\text { ESTETICA } \\
\text { DESIGN }\end{array}$ & $\mathrm{N}^{\circ} 6$ - July 2006 Issue (102 pages) & $\begin{array}{l}\text { Architecture and Interior } \\
\text { Design }\end{array}$ \\
\hline FRAME & $\mathrm{N}^{\circ} 51$ - July/August 2006 Issue (209 pages) & Interior Design, Product Design \\
\hline VANITY FAIR & August 2006 Issue (148 pages) - UK Edition & Fashion, Lifestyle and People \\
\hline Website Name & $\begin{array}{l}\text { URL (all websites version from } \\
\text { July 25, 2006) }\end{array}$ & Sector \\
\hline Ads of the world & adsoftheworld.com & Advertising \\
\hline Car Design News & www.cardesignnews.com & Automotive Design \\
\hline Design Goodness & www.frederiksamuel.com/blog/ & Design - Advertising \\
\hline Design*sponge & www.designsponge.blogspot.com & Design \\
\hline Inside-photo.com & www.inside-photo.com & Architecture \\
\hline MoCo Loco & www.mocoloco.com & Product Design \\
\hline My Fashion Life & www.myfashionlife.com & Fashion and People \\
\hline Style 4 Cars & www.style4cars.com & Automotive Design \\
\hline Truc design & www.trucdesign.com & Product Design \\
\hline Wallpaper* & www.wallpaper.com/architecture & Architecture and Design \\
\hline
\end{tabular}




\section{Inspiration, images and design}

All magazines and websites used in the experiment dealt with creative sectors that were identified as usual sectors of reference by car-designers in the semi-structured interviews (e.g. car-design, architecture, interior design). In this first step, designers were asked to identify inspirational content, but the search did not have to target any specific issue. This was intended to simulate a situation close to the designers' usual continuous monitoring of trends and designs. Without any brief or any directions, designers were invited to browse freely magazines first, and then websites. All retrieved images were recorded, as well as the search terms that participants used. Participants were then asked to identify which components of each image led to their decision on inspirational content. Prompts of shape, colour, texture, and semantics were given. The participants wrote down this information on sticky notes that were associated with the selected pictures. When the pictures collecting task was over, designers were invited to categorise the pictures and to choose words to name the categories (Figure 5).

The total duration of this task was about 1 hour for each participant.

\subsubsection{Constrained exploration of visual resources}

In the second stage of the experiment, participants completed a focused image-search; the search was so-called 'focused' because it was constrained by a design brief which gave conditions about sociological and emotional values that needed to be integrated into the targeted design. The design brief is detailed in Figure 6.

Figure 5 Steps of the exploration and categorisation of visual resources

\begin{tabular}{|c|c|c|c|}
\hline $\begin{array}{l}\text { Selecting images that } \\
\text { are found inspirational } \\
\text { from magazines }(6)\end{array}$ & $\begin{array}{c}\text { Annotating the } \\
\text { images with sticky } \\
\text { notes }\end{array}$ & $\begin{array}{l}\text { Grouping the } \\
\text { images }\end{array}$ & $\begin{array}{l}\text { Naming the } \\
\text { groups of } \\
\text { images }\end{array}$ \\
\hline $\begin{array}{l}\text { Selecting images that } \\
\text { are found inspirational } \\
\text { from websites }(10)\end{array}$ & $\begin{array}{l}\text { Annotating the } \\
\text { images by giving } \\
\text { names to the jpg files }\end{array}$ & $\begin{array}{l}\text { Grouping the } \\
\text { images }\end{array}$ & $\begin{array}{l}\text { Naming the } \\
\text { groups of } \\
\text { images }\end{array}$ \\
\hline
\end{tabular}

Figure 6 Design brief given to the participants before the images search

Target car-maker: European car-maker

Target customers: Young male driver in his 20's

Type of vehicle: "Zinedine Zidane" Roadster

Based on the sport vehicles segment, this new roadster should embody the spirit and the values of the soccer idol, Zinedine Zidane.

Figure 7 Steps of the constrained exploration of visual resources

\begin{tabular}{|c|c|c|c|}
\hline $\begin{array}{l}\text { Receiving a } \\
\text { design brief }\end{array}$ & $\begin{array}{l}\text { Giving keywords } \\
\text { inspired by the brief }\end{array}$ & $\begin{array}{l}\text { Using the keywords to } \\
\text { retrieve images from } \\
\text { online picture tanks }(6)\end{array}$ & $\begin{array}{l}\text { Selecting the images } \\
\text { found inspirational }\end{array}$ \\
\hline
\end{tabular}




\section{Mougenot et al.}

At first, participants had to write down the keywords that came to their mind when reading the design brief. Then participants were invited to browse a selection of pictures from websites, most of them being designed for professional users (Corbis, Fotolia, Getty, Google Images, Inside, Masterfile). They could use the words that first came to their mind as keywords for their requests. While browsing these websites, participants had to select pictures to illustrate the design brief as if they would use these pictures for a trend board illustrating a design proposal. The selected pictures were saved by the participants on the computer hard disk. During the process of picture selection, participants verbally explained their choices and notes were taken by the experimenter. See Figure 7 for an overview of this component of the experiment.

The total duration for this task was about $40 \mathrm{~min}$ for each participant.

\subsection{Outcomes}

\subsubsection{Magazines and websites unconstrained exploration by designers}

Number of retrieved images - while browsing magazines and websites, participants selected the pictures they found inspirational. The first observation concerns the total number of pictures retrieved either from printed medium, i.e. 55 pictures, or in online medium, i.e. 31 pictures. While the participants were given the same time allocation for both browsing tasks, it is obvious that they found a greater quantity of inspirational materials through the magazines than on websites (Figure 8).

Figure 8 Samples of images from magazines that were found inspirational by designers (see online version for colours)

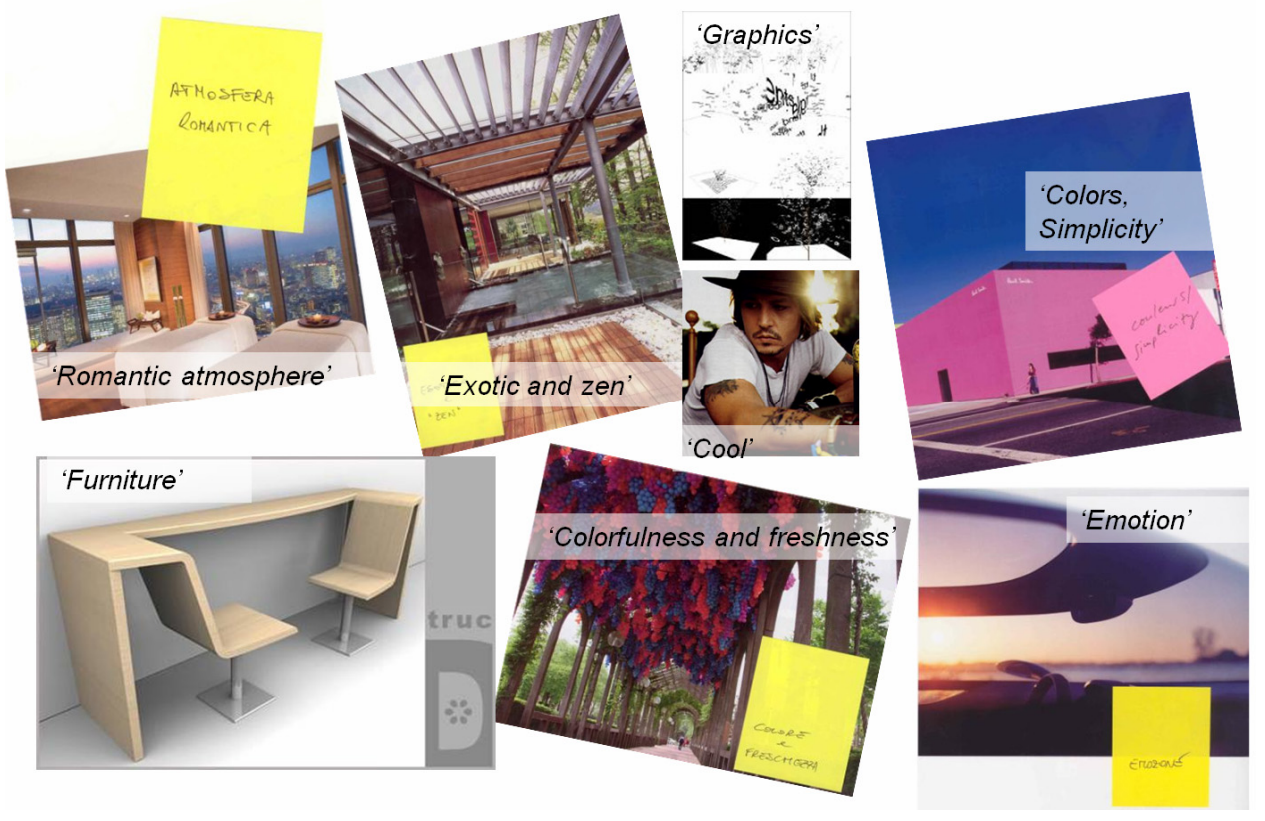




\section{Inspiration, images and design}

Commonalities between sets of selected pictures - Figure 9 shows the only picture that was selected by more than one participant (two participants picked this picture, both describing it with the concept of 'simplicity' and both classifying it in a 'shape'-related category. Designer 1 used this picture description to name a whole category. This is an interesting finding: given a finite and rather small images database made of six printed magazines, participants make images selections that are very different from one to another.

Type of images selected - in the magazines browsing tasks, 55 pictures were retrieved by the four participants. Most of the selected pictures were A4-magazine page format (cf. Table 2). The selected pages showed a very clear focus on a specific subject, without any text most of the time. Pages full of small details were not popular: only five images (out of 55) were a selection within a page full of details (graphical or shape details).

Figure 9 Description by participants about the only image selected more than once (see online version for colours)

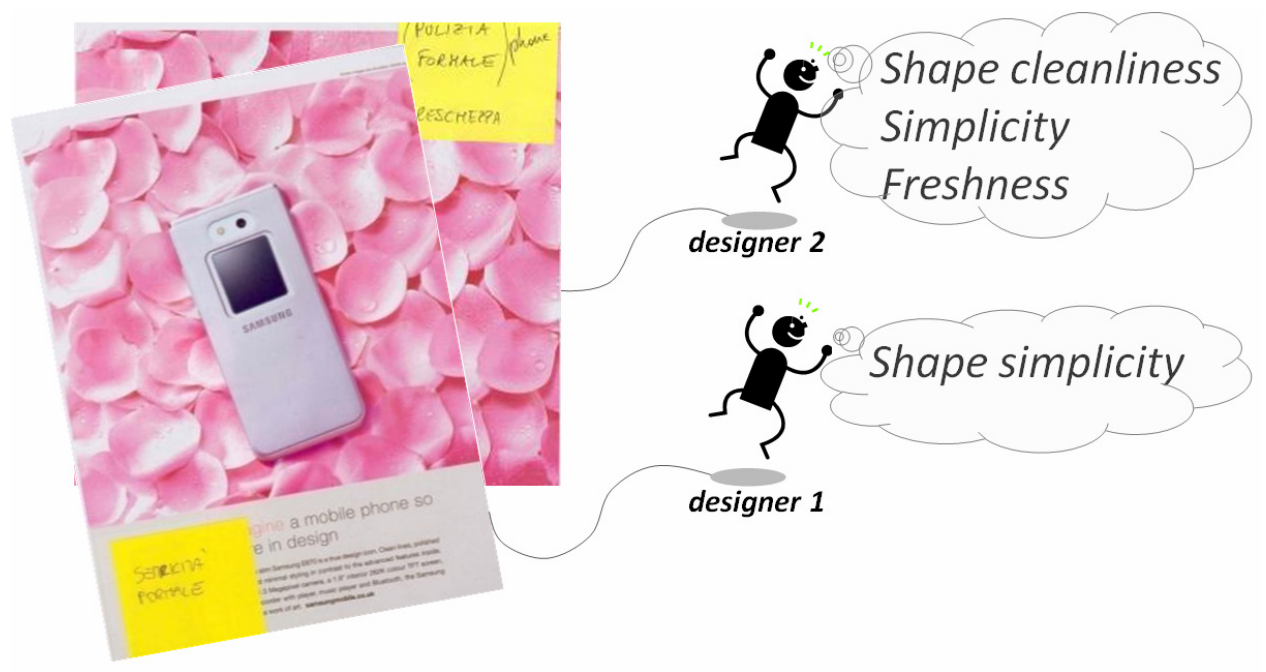

Table 2 Format types for images selected by the participants (over 55 selected pictures) (see online version for colours)

\begin{tabular}{llll}
\hline Format & A4-format picture & A4-format & A3-format picture \\
\hline $\begin{array}{l}\text { Visual information } \\
\text { Lexical information }\end{array}$ & One single subject & More than 1 subject & One single subject \\
\% of this type in & $80 \%$ & Lot of text & No text \\
the selection & $9.1 \%$ & $10.9 \%$ \\
Example given & & & \\
\end{tabular}




\section{Mougenot et al.}

Six selected images were A3-format (magazine double-pages). All were selected by the same designer who also created many categories linked with feelings and 'atmospheres'. An explanation for this selection could be that large-format images better involve the observer in the atmosphere of the picture.

Sources of influence - from the six magazines proposed by the experimenters, the participants selected between three and five magazines to be browsed during a limited time $(30 \mathrm{~min})$. The participants selected inspirational pictures in quite similar sets of magazines among the proposed magazines: FRAME and DAM were the most popular magazines for the pictures selection, while ELLE and VANITY FAIR were the most often left aside. The four participants selected a total of 55 pictures. The overall selection of pictures is broken down as described in Figure 10, with respect to each source.

The content of the selected images can be described as intra-domain sources, close interdomain sources and far inter-domain sources, depending on the amount of shared properties with the products to be designed (in our case: cars). The definitions of these categories are given in Table 3, along with the examples of content as would apply in this study

Following these definitions, the experimenters allocated the retrieved images to the three domain categories, as shown in Figure 11. At this stage, the analysis was mainly based on the content of the images, as judged by the experimenters and independent from the participants' perception of the images.

In both cases of retrieval, magazines and websites, the relative preference for domains is similar. It is noticeable that the least numbers of image were selected from intradomain sources and remote inter-domain sources, while the greatest number of images was selected from close inter-domain sources ( $88 \%$ of magazines selection and $71 \%$ of websites selection).

Figure 10 Distribution of the amount of selected pictures with respect to the source magazines (e.g. 29\% of the total number of selected images came from 'Frame') (see online version for colours)

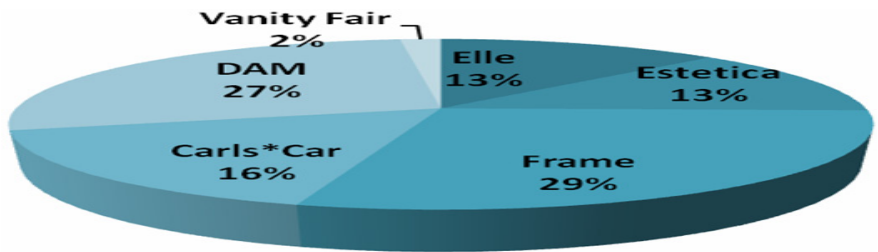

Table 3 Definition of sources domains [Adapted from (Bonnardel, 2005)]

\begin{tabular}{lll}
\hline Type of sources & Definition & Example content \\
\hline Intra-domain & $\begin{array}{l}\text { The source is from the same semantic } \\
\text { domain as the product to be designed. }\end{array}$ & Car and transportation design. \\
Close inter-domain & $\begin{array}{l}\text { The source has some common properties } \\
\text { with the product to be designed. }\end{array}$ & Product design. Architecture \\
Far inter-domain & $\begin{array}{l}\text { The source is obviously different from the } \\
\text { product to be designed. }\end{array}$ & Fashion. Lifestyle. People. \\
\hline
\end{tabular}




\section{Inspiration, images and design}

Figure 11 Number of retrieved images (magazines/websites) for each source domain (see online version for colours)

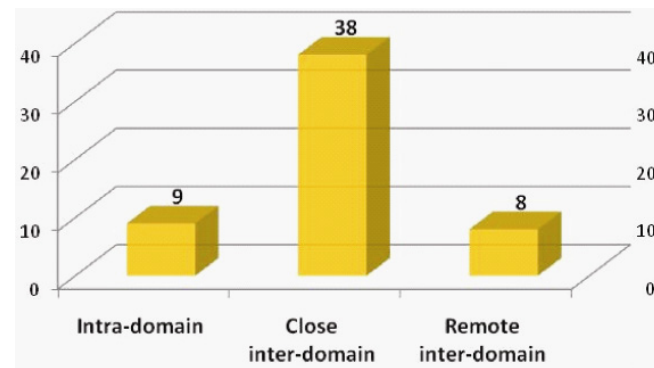

Images retrieved from printed magazines (total number of retrieved images $=55$ )

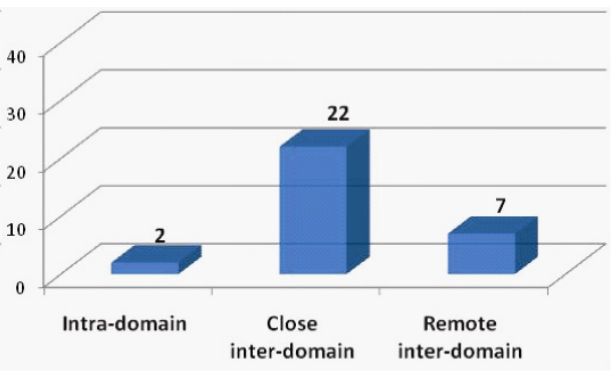

Images retrieved from websites $($ total number of retrieved images $=31$ )

$x$-axis: reference domain $-y$-axis: percentage of retrieved images

Table 5 Definition of abstraction levels

\begin{tabular}{lll}
\hline Abstraction level & Types of features & Examples from our case study \\
\hline High & Emotions, atmospheres and feelings & Cool, Provocation \\
Mid & Products or sectors & Architecture, Products \\
Low & Materials, colours, textures & Colours, Shapes \\
\hline
\end{tabular}

Abstraction level of the image content - participants had to group their retrieved images and to give names to the created categories. The category names given by all four participants can be found in Table 4. At one extreme, design descriptions can be 'lowlevel' and linked to the physical characteristics of a product. At the other extreme, design descriptions can be 'high-level' and related to designer interpretation of affective and semantic image content. He we consider three levels of abstraction to describe image content: high, mid and low. Definitions are given in Table 5, as well as some examples of the categories created by the participants in this experiment.

Following these definitions, the images retrieved by the participants were distributed by the experimenters to one of the three levels of abstraction, as shown in Table 4 . Some images could belong to several levels of abstraction; for instance, an image of the 'Shape simplicity' group could be allocated to both the low abstraction level (shape) and the high abstraction level (simplicity). At this stage, the analysis was mainly based on the names given by the participants to the images groups, thus it is based on the participants' perception of the images they retrieved.

As shown in Figure 12, the content of the images was very different depending on whether the images were retrieved from magazines or websites. When assessing the level of abstraction for each categories created by the designers, it appeared that $41.4 \%$ of the pictures found in the magazines were classified in the 'high-level' category, i.e. linked to an affective or a semantic description, while only $25 \%$ of the pictures found on the internet fell into this category level. The high-level category often refers to an atmosphere triggered by the visual information. Actually, the internet seems to provide pictures that are very often categorised at a mid-level of abstraction, more than $60 \%$, linked to a product or to a creative sector (Car, Furniture). 


\section{Mougenot et al.}

Table 4 Categories created by the designers and associated number of pictures ${ }^{1}$

\begin{tabular}{|c|c|c|c|c|}
\hline $\begin{array}{l}\text { Number of images retrieved } \\
\text { from magazines }\end{array}$ & & $\begin{array}{l}\text { Number of images retrieved } \\
\text { from websites }\end{array}$ & & $\begin{array}{l}\text { Level of abstraction } \\
\text { (by the experimenters) }\end{array}$ \\
\hline Miscellaneous & 4 & & 0 & $\rightarrow$ Undefined \\
\hline Graphics & 8 & Sketches & 1 & \\
\hline Textures & 2 & Backgrounds & 3 & \\
\hline Colors & 2 & & & \\
\hline Shapes (harmonies dynamics) & 10 & & & \\
\hline Shapes (simplicity) & 4 & & & \\
\hline Total & 26 & & 4 & $\rightarrow$ Low level \\
\hline Objects and shapes & 2 & Objects & 3 & \\
\hline Product design & 4 & Products & 1 & \\
\hline Garage & 3 & Car & 1 & \\
\hline \multirow[t]{2}{*}{ Architecture } & 2 & Furniture/Interior Design & 6 & \\
\hline & & Graphics & 8 & \\
\hline Total & 11 & & 19 & $\rightarrow$ Mid-level \\
\hline Impressions & 2 & Provocation & 2 & \\
\hline (Shapes) harmonies dynamics & 10 & Atmosphere & 5 & \\
\hline (Shapes) simplicity & 4 & Cool & 1 & \\
\hline \multirow{2}{*}{$\begin{array}{l}\text { Ambiences atmospheres } \\
\text { emotions }\end{array}$} & 3 & & & \\
\hline & 2 & & & \\
\hline Cool & 4 & & & \\
\hline Atmosphere & 4 & & & \\
\hline \multicolumn{5}{|l|}{ Style } \\
\hline Total & 26 & & 8 & $\rightarrow$ High level \\
\hline
\end{tabular}

Figure 12 Number of retrieved images (magazines/websites) for each abstraction level (see online version for colours)
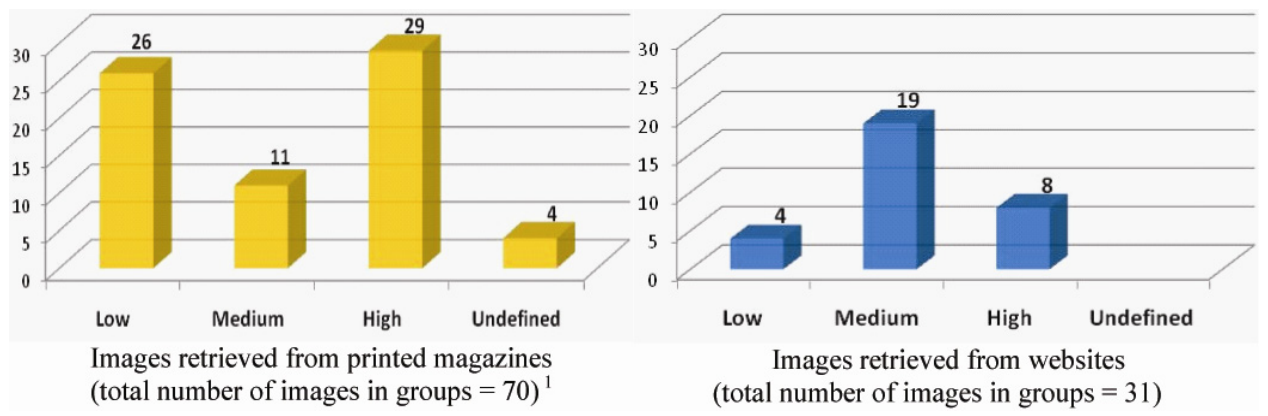

$x$-axis: level of abstraction of the image content $-y$-axis: number of images 


\section{Inspiration, images and design}

\subsubsection{Image-search constrained by a design brief}

Sector of reference: car-design - after having received the design brief, all designers started their search task with a very clear idea of a car-model that would fit the brief requirements. All four designers named car brands or car-models aloud, Smart, Renault and $B M W Z 4$ by two of them. Two participants started the task by sketching the car model they were thinking of (inspired by Smart and by Renault brands) and two others initiated an internet search with requests about $B M W Z 4$. Without any brief, participants tended to look for images that were not specifically related to car-design sector, while with the brief constraint, all participants seemed to head spontaneously toward intradomain sources, in their case: car-design.

Subjectivity integration into web request - the brief dealt with Zinedine Zidane spirit. In consequence it was expected that designers would try to find pictures to illustrate abstract elements, such as sociological values, emotions or personality features. The key results for this task were twofold: firstly the designers wrote down a list of lexical terms they spontaneously associated with the brief statement, secondly the designers launched internet searches based on the list of words they wrote down. It is interesting to look at the gap between the first ideas that came to the participants' mind right after listening to the brief and the actual results of the internet requests that were meant to illustrate their first ideas. When focusing on the strategy adopted by 'designer 1', we noticed that, after listening to the brief, 'designer 1' wrote down the following words: versatile, accessories, fun, 2-sear car, city, zainetto; he also sketched a zainetto car model. He then started a search with picture-search engines, with a strategy described in Table 6.

Table 4 'Designer 1' strategy to retrieve images in the brief-constrained task (see online version for colours)

\begin{tabular}{|c|c|c|c|}
\hline Step & Search engine & Keyword & Retrieved images \\
\hline 1 & CORBIS & Zainetto & No satisfying image \\
\hline 2 & CORBIS & Zainetto + Bag & No satisfying images \\
\hline 3 & CORBIS & Zainetto + Back bag & No satisfying images \\
\hline 4 & GOOGLE & Zaino Seven & \\
\hline 5 & GOOGLE & Bag & \\
\hline 6 & GOOGLE & City & No satisfying images \\
\hline 7 & GOOGLE & Traffic & 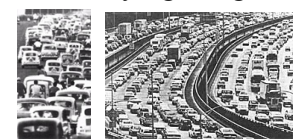 \\
\hline 8 & GETTY & Fun & No satisfying images \\
\hline 9 & GETTY & Versatile & No satisfying images \\
\hline 10 & GETTY & Sport & \\
\hline 11 & FOTOLIA & $\varnothing$ & No satisfying images \\
\hline
\end{tabular}




\section{Mougenot et al.}

'Designer 3' found pictures with the following keywords: BMW Z4, Lotus Exige, Zidane, Football; he was satisfied with the associated findings. To designers 1, 2 and 4, most of request results were not satisfying. The pictures they selected were found by chance, and not thanks to the keywords that were keyed in the search engine dialog box. With the internet, most requests retrieved images that did not fit the participants' expectations.

\section{Discussion}

Web tools transform designers' activity - in the free browsing tasks, we observed that the designers did not retrieve the same materials when they browse printed magazines as when they browse websites. For instance, the pictures retrieved from the magazines mainly belonged to an 'affective and semantic' level (41.4\%), while the pictures selected on websites mainly illustrated 'Products' and 'Sectors' (61.3\%). In addition, when fulfilling a design brief, we observed a gap between the designers' intention (keywords) and the web request results/picture selection. Three of the four designers were not satisfied with the results provided by image-search engine, because they felt the retrieved images did not correctly illustrate the ideas behind the keyword used in their requests. We also notice that the designers adapted their searching strategies to compensate for perceived limitations of the web. For instance, to illustrate a rather abstract idea (Competition), a participant used other keywords that he thought would be more likely to be understood by the web engine (Footwear, then Footwear + Sport, then Footwear + Sport + Design).

Individual strategies based on common design culture - consistent with Visser (2006), we found that the design process comprises commonalities and individual specificities. Our study demonstrates this in the frame of the information gathering phase. All four designers were provided with the same set of information sources; within these sources, they made some common global selections, for instance, they all rejected VANITY FAIR magazine and they all spent a long time flickering through FRAME magazine. The sectors the designers refer to, in their informational search, were quite similar; all of them were targeting product design sector and architecture sector. While there is a common ground for the inspirational materials retrieval, i.e. common 'sectors of reference', only one image out of the 55 selected out of the magazines was selected by more than one participant. Consistent with this emphasis on individuality are results relating to the types of categories designers created to classify the pictures they found inspirational. These varied from low-level categories (Colours, Textures) to high-level categories (Cool, Simplicity) through sectors names (Architecture, Garage). This classification seemed to be very personal. 'Designer 4' created only 'sectors' categories (Architecture, Product Design) while 'Designer 2' named four among his five categories with high-level descriptions (Cool, Style, Impressions, Atmospheres); 'Designer 1' and 'Designer 3' provided a mixed classification. When asked to illustrate a 'Zidane roadster' with any picture of their choice, all designers first started by giving a car-design reference, respectively, Smart, Renault, BMW Z4 and BMW Z4. Referring to car-design precedents seemed to be a shared characteristic of our participants. However, in the following steps of the assignment participants followed rather individual strategies. For instance, they either tried to illustrate high-level characteristics (Popular, Versatile, Fun) or launched 


\section{Inspiration, images and design}

requests about concrete elements (Zidane, BMW Z4, Lotus Exige). The participants performed searching sequences very dissimilar from each other.

To summarise, the participants shared common interest for specific domains (e.g. car design, architecture) and for specific media (e.g. architectural magazines, cardesignnews website) but they followed very individual strategies when they had to search for inspirational pictures (e.g. they used different keywords in the pictures search engines, and they classified magazines images at different abstraction levels).

Designers' Kansei in the informational activity - $41.4 \%$ of the pictures selected in the magazines were described with lexical terms linked to a feeling or an atmosphere. A significant part of the information gathering phase of the design process is concerned with the feelings of the designer. The designers' feelings relating to the productare possibly integrated in information searches made with traditional tools (printed media) but not fully expressed when surfing the internet. The internet provides images that are mainly described by mid-level descriptors, as if neither detailed enough for providing low-level descriptors (colours, shapes) nor subjective enough for bringing feelings, emotions, or a sensation for atmospheres. From the very first results of our analysis, this might be caused by the images formats (images on the web are often of very small size) and by the images quality (images on the web might not have been taken by professional photographers and might not be displayed correctly). Previous studies showed the importance of designers' subjectivity (kansei) within the design process. Our study specifically demonstrates the importance of designers' kansei in the informational phase, as designers search for inspiration and design information.

\section{Conclusions}

This two-part study was performed in a car-design context, yet some generic elements of the results may be useful for all design-related activities that include searching information for design.

First, it seems that there are differences in the way that different media are used in the context of the design process. When designers search for inspirational materials, we observed that they use the internet, in a different way to printed magazines.

Second, there may be limitations in current electronic tools that constrain their use. For example, in the study reported it was apparent that designers altered their requests (the keywords used) to adapt to limitations of the computational tools available. This may be because they were not well suited to designers' requirements for expressing and locating images based on feeling-related concepts that were considered inspirational with regard to the design subject.

Third, today's computational tools could allow more effective control, such that individual differences in information gathering strategy can be more effectively pursued. For example, in this study it was apparent that designers differed in their preference for locating inspirational materials at various levels of abstraction. When browsing images some designers would rather look for 'high level' constructs, such as atmospheres, while others would rather look for low-level constructs such as specific colours or shapes: Computer tools that effectively support this type of flexibility would be advantageous.

In summary, we suggest that designers' creativity will be more efficiently supported by computational tools when these tools take better account of differences in image 


\section{Mougenot et al.}

content as it pertains to the design task. This includes providing search facilities that are more flexible with respect to the specification of level of abstraction in image content and that provide greater emphasis on emotional content. On this basis future research should deal with designers' kansei and creativity, not only in the phases of ideas generation, but in the early information gathering and inspirational phases as well. This challenging topic will impact the way computational tools for creativity support will be developed and provide a better understanding of fruitful sources of information and inspiration.

\section{Acknowledgement}

The authors are grateful to the European Commission who supported this research and the related project called TRENDS, through the 6th Framework Program for Information Society Technologies (FP6-27916). They also would like to thank Stile Bertone and FIAT designers for their useful and friendly participation to the experiments.

\section{References and bibliography}

Ahmed, S. (2007) 'Empirical research in engineering practice', Journal of Design Research, Special Issue on Empirical Approaches in Design Information and Knowledge, Vol. 6, pp.359-380.

Ansburg, P.I. and Hill, K. (2003) 'Creative and analytic thinkers differ in their use of attentional resources', Personality and Individual Differences, Vol. 34, pp.1141-1152.

Badke-Schaub, P. (2007) 'Creativity and innovation in industrial design: wishful thinking?', Journal of Design Research, Vol. 5, pp.353-367.

Bonnardel, N. and Marmèche, E. (2005) 'Towards supporting evocation processes in creative design: a cognitive approach', Int. J. Human-Computer Studies, Vol. 63, pp.422-435.

Bouchard, C., Lim, D. and Aoussat, A. (2003) 'Development of a Kansei engineering system for industrial design - identification of input data for KES', Sixth Asian Design International Conference, ADC, Tsukuba, Oct. 14-17.

Bouchard, C., Aoussat, A. and Duchamp, R. (2006) 'Role of sketching in conceptual design of car styling', Journal of Design Research, Vol. 5, pp.116-148.

Bouchard, C., Omhover, J.F., Mougenot, C. and Aoussat, A. (2008) 'TRENDS: a content-based information retrieval system for designers, DCC'08', Third Conference on Design Computing and Cognition, Atlanta, June 21-23, 2008.

Casakin, H. and Goldschmidt, G. (1999) 'Expertise and the use of visual analogy: implications for design education', Design Studies, Vol. 20, pp.153-175.

Christiaans, H. and Restrepo, J. (2001) 'Information processing in design: a theoretical and empirical perspective', in H. Achten, B. de Vries and J. Hennessey (Eds), Design Research in the Netherlands. Eindhoven: TU, pp.63-73.

Cross, N., Christiaans, H. and Dorst, K. (1996) 'Introduction: the Delft protocols workshop', in Cross, N., Christiaans, H. and Dorst, K. (Eds), Analysing Design Activity. Chichester: Wiley, pp.1-16.

Eckert, C.M. and Stacey, M.K. (2000) 'Sources of inspiration: a language of design', Design Studies, Vol. 21, pp.523-538.

Goldschmidt, G. and Smolkov, M. (2006) 'Variances in the impact of visual stimuli on design problem solving performance', Design Studies, Vol. 27, pp.549-569. 


\section{Inspiration, images and design}

Guénand, A. and Capell Zapata, F. (2003) 'A reference system of semantic characterisation of products based on an ontology', Sixth Asian Design International Conference, ADC, Tsukuba, October $14-17$.

Keller, A.I. (2005) For Inspiration Only: Designer Interaction with Informal Collections of Visual Material. PhD thesis, T.U. Delft, The Netherlands.

Keller, A.I., Stappers, P.J. and Hoeben, A. (2000) 'TRI: inspiration support for a design studio environment', Int. J. Design Computing, Vol. 3, p.17.

Kolli, R., Pasman, G. and Hennessey, J. (1993) 'Some considerations for designing a user environment for creative ideation', Proceedings of the Interface'93, North Carolina State University, Raleigh, NC, pp.72-77.

Lawson, B. (1980, 2006) How Designers Think: The Design Process Demystified (4th ed.). Oxford: Architectural Press.

Lawson, B. (2004) 'Oracles, draughtsmen and agents: the nature of knowledge and creativity in design and the role of IT', Automation in Construction, Vol. 14, pp.383-391.

Leclercq, P. and Heylighen, A. (2002) '5.8 Analogies per hour - a designer's view on analogical reasoning', AID'02 Artificial Intelligence in Design, Cambridge, July 15-17.

Levy, P. and Yamanaka, T. (2006) 'Towards a definition of Kansei', Wonderground - Design Research Society International Conference, Lisbon, November 1-4.

Mougenot, C., Bouchard, C. and Aoussat, A. (2006) 'Fostering innovation in early design stage: a study of inspirational process in car-design companies', Wonderground, The Design Research Society International Conference, Lisbon, November 1-4.

Muller, W. and Pasman, G. (1996) 'Typology and the organization of design knowledge', Design Studies, Vol. 17, pp.111-130.

Nagai, Y., Candy, L. and Edmonds, E. (2003) 'Representations of design thinking', Sixth Asian Design International Conference, ADC, Tsukuba, October 14-17.

Nakakoji, K., Yamamoto, Y. and Ohira, M. (1999) 'A framework that supports collective creativity in design using visual images', Proceedings of the third conference on Creativity \& Cognition, Loughborough, UK, pp.166-173.

Pasman, G. (2003) Designing With Precedents. Ph.D. Thesis. T.U. Delft, The Netherlands.

Perttula, M. and Sippilä, P. (2007). 'The idea exposure paradigm in design idea generation', Journal of Engineering Design, Vol. 18, pp.96-102.

Restrepo, J. (2004) Information Processing in Design (Design Science Planning). Delft: Delft University Press.

Schön, D. (1983) The Reflective Practitioner. How Professionals Think in Action. London: Temple Smith.

Schneiderman, B. (2000) 'Creating creativity: user interfaces for supporting innovation', $A C M$ Transactions On Computer-Human Interaction, Vol. 7, pp.114-138.

Visser, W. (2006) 'Both generic design and different forms of designing', Wonderground - Design Research Society International Conference, Lisbon, November 1-4.

Westerman, S.J., Kaur, S., Dukes, C. and Blomfield, J. (2007) 'Creative industrial design and computer-based image retrieval: The role of aesthetics and affect', ACII2007, Proceedings of the Conference on Affective Computing and Intelligent Interaction, Lisbon, September 2007.

\section{Note}

${ }^{1}$ Some of the pictures were allocated to several categories. 